\title{
Assessment of Startle Response and Its Prepulse Inhibition Using Posturography: Pilot Study
}

\author{
Jacek Polechoński, ${ }^{1}$ Grzegorz Juras, ${ }^{1}$ Kajetan Słomka, ${ }^{1}$ Janusz Błaszczyk, ${ }^{1,2}$ \\ Andrzej Małecki, ${ }^{1}$ and Agnieszka Nawrocka ${ }^{1}$ \\ ${ }^{1}$ The Jerzy Kukuczka Academy of Physical Education in Katowice, Katowice, Poland \\ ${ }^{2}$ Nencki Institute of Experimental Biology, Warsaw, Poland \\ Correspondence should be addressed to Agnieszka Nawrocka; a.nawrocka@awf.katowice.pl
}

Received 21 January 2016; Accepted 26 April 2016

Academic Editor: Margaret A. Niznikiewicz

Copyright (C) 2016 Jacek Polechoński et al. This is an open access article distributed under the Creative Commons Attribution License, which permits unrestricted use, distribution, and reproduction in any medium, provided the original work is properly cited.

\begin{abstract}
Purpose. The aim of this study was to evaluate the possibility of using static posturography in the assessment of sensorimotor gating. Subjects and Methods. Fourteen subjects took part in the experiment. The inhibitory mechanisms of startle reflex were used as the measure of sensorimotor gating. It was evoked by a strong acoustic stimulus (106 dB SPL, $40 \mathrm{~ms}$ ) which was preceded by the weaker similar signal ( $80 \mathrm{~dB}$ SPL, $20 \mathrm{~ms}$ ). A stabilographic platform was used to measure sensorimotor gating. Results. Results of static posturography show that the postural sway caused by the reaction to a strong acoustic stimulus is significantly smaller when this stimulus is preceded by the signal of lower intensity (prepulse). Such assessment is only possible in eyes open conditions. Conclusions. Static posturography can be simple and effective method used for diagnosis of sensorimotor gating in humans.
\end{abstract}

\section{Introduction}

Sudden and strong acoustic signal causes orienting response prior to which a specific motor reaction can be observed. This response is called acoustic startle reflex (ASR) and can be decreased by prepulse inhibition (PPI), when a slight stimulus is previously generated. PPI is currently perceived as the measure of sensorimotor gating, being the ability of the nervous system to filter irrelevant information [1].

Assessment of sensorimotor gating is useful especially in neurological and psychiatric research. A lot of studies have shown that PPI is disturbed in many diseases and disorders, for example, schizophrenia [2-5], Alzheimer's disease [6], Multiple System Atrophy (MSA) [7], Parkinson's disease [8], generalized dystonia [9], and subcategory of autism, Asperger syndrome [10].

Startle response (startle reflex) is usually recorded using electromyography (EMG) and concerns the assessment of orbicularis oculi muscle activation [11-14]. It might be problematic, for example, in case of excessive blinking which can be an effect of nervous hyperactivity or motor tics. Therefore, the recording activity of and muscles (masseter, sternocleidomastoid, biceps brachii, abductor pollicis brevis) also is used in the assessment of startle reflex, $[9,15,16]$. Brown et al. [17] examined startle response caused by acoustic stimulus on leg muscles (tibialis anterior, soleus). However, such measurements are complicated and time-consuming. Experiments conducted on animals have shown that special force platforms can be used for assessment of startle response $[18,19]$.

The aim of this study was to evaluate the possibility of using the static posturography for assessment of the sensorimotor gating and startle reflex in human. The potential results of this study could be useful in diagnosis of patients with neuronal and psychological disorders.

\section{Material and Methods}

Studies have been approved by the Bioethical Commission of the Jerzy Kukuczka Academy of Physical Education in Katowice. Fourteen male students participated in the study (age $21.9 \pm 1.1$ years, height $182.2 \pm 8.9 \mathrm{~cm}$, and weight 


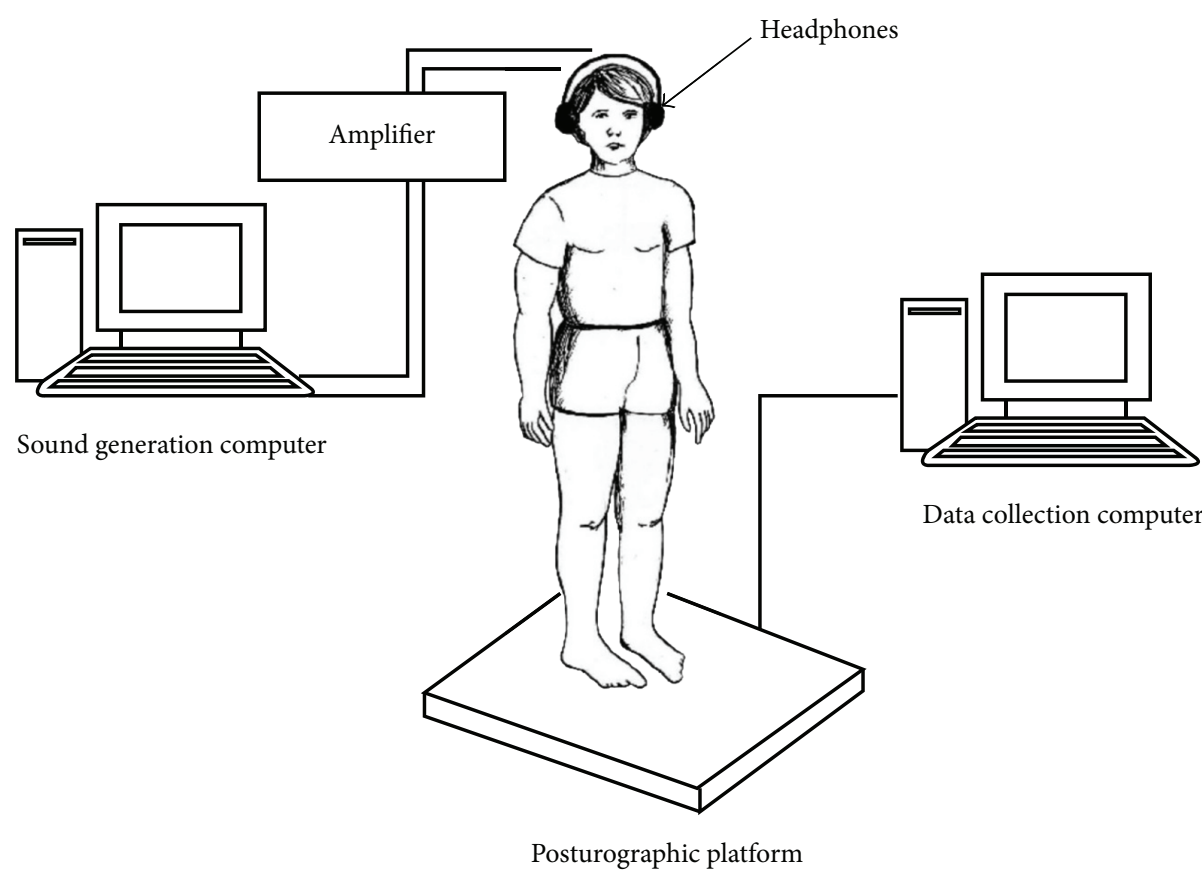

FIgURE 1: Experimental setup.

$78.6 \pm 11.4 \mathrm{~kg}$ ). The following exclusion criteria were specified: postural and auditory disorders and neurological or psychiatric deficits.

The centre of pressure (COP) sway in anterior-posterior (AP) and mediolateral (ML) directions was registered (at $40 \mathrm{~Hz}$ sampling frequency) using stabilographic platform (QFP/Medicapteurs, France) with Winposture 2000 software. Subjects were provided with acoustic pulses generated by Audacity software (release 1.2.4) and amplified by an external amplifier (UNITRA, model PW8010). The stimuli were delivered through headphones worn by each subject throughout the experiment (Figure 1).

Subjects were instructed to stand quietly on a stabilographic platform in a comfortable position with their arms along their sides. Each subject performed two trials with eyes open and two trials with eyes closed. The experimental procedure design was based on a similar study by Grillon et al. [20]. Startling stimuli ( 3 x $106 \mathrm{~dB}, 40 \mathrm{~ms})$ were presented alone or were preceded by prepulse stimuli $(3 \mathrm{x} 80 \mathrm{~dB}, 20 \mathrm{~ms})$ over a steady background noise $(70 \mathrm{~dB})$. The time between prepulse stimulus and startle stimulus was $120 \mathrm{~ms}$ (Figure 2). Analysis of posturographic parameters were conducted within $1.5 \mathrm{~s}$ after the startle stimuli were provided. Together six reactions to the stimulus and six reactions preceded by the prepulse stimulus were analyzed for each subject.

2.1. Statistical Analysis. Two-way analysis of variance (ANOVA) for repeated measures was used to determine the differences between responses to the different acoustic stimuli. The significance level was set at $p<0.05$. All statistical analyses were performed using the Statistica software (9.0).

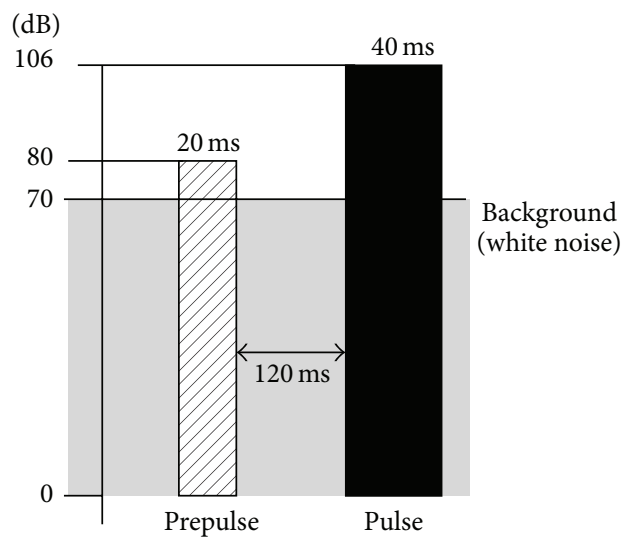

FIGURE 2: Time intervals and sound intensity of the acoustic stimuli.

\section{Results}

The results of analysis in ML plane with eyes open show a significant effect of kind of stimulus on lateral sway, which was reduced when a sudden acoustic signal was preceded with prepulse stimulus $(p<0.005)$ (Table 1$)$. In the rest of the trials there was no significant influence of stimulus kind (without Prepulse, with Prepulse) on the COP sway. Regardless of the plane and visual control, analysis of variance did not show a significant effect of the signals order on the amplitude of COP displacement (Table 1).

In all consecutive acoustic stimuli with eyes open trial, weaker startle responses were observed when the signal was preceded with prepulse stimulus. However, the significant 
TABLE 1: The influence of the kind (without prepulse, with prepulse) and order of the acoustic stimuli on the COP displacement.

\begin{tabular}{lcccccrrr}
\hline & \multicolumn{4}{c}{ Eyes open } & \multicolumn{4}{c}{ Eyes closed } \\
Variables & \multicolumn{2}{c}{ Anterior-posterior } & \multicolumn{2}{c}{ Mediolateral } & \multicolumn{2}{c}{ Anterior-posterior } & \multicolumn{2}{c}{ Mediolateral } \\
& $F$ & $p$ & $F$ & $p$ & $F$ & $p$ & $p$ \\
\hline Stimulus kind & 2.352 & 0.149 & 14.102 & $\mathbf{0 . 0 0 2}$ & 0.179 & 0.679 & 0.007 & 0.935 \\
Stimulus order & 0.130 & 0.879 & 0.604 & 0.554 & 0.435 & 0.652 & 0.328 & 0.724 \\
Stimulus kind $\times$ stimulus order & 0.875 & 0.429 & 0.146 & 0.865 & 0.948 & 0.400 & 0.244 & 0.785 \\
\hline
\end{tabular}

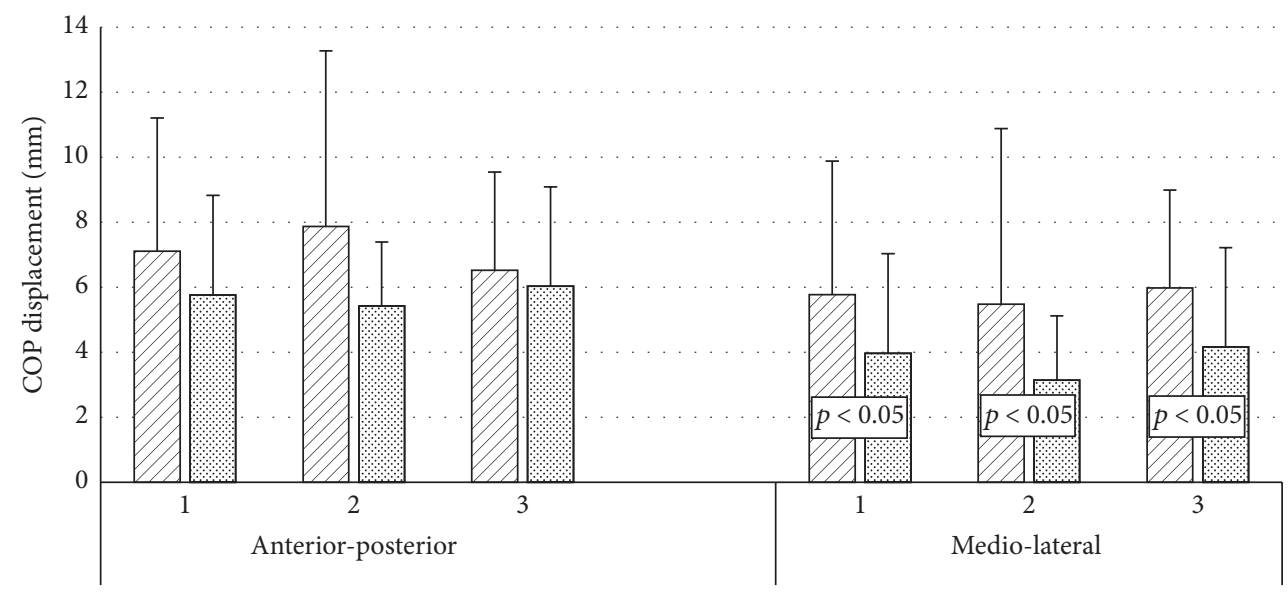

Without prepulse

With prepulse (PPI)

FIgure 3: COP displacement depending on the kind (without Prepulse, with Prepulse) and order $(1,2,3)$ of the acoustic stimulus in eyes open trials.

differences were found only in mediolateral plane. In three repetitions of acoustic stimuli, prepulse stimulus caused significant reduction of mediolateral COP displacement (Figure 3).

In all trials with eyes closed, the acoustic stimuli did not significantly influence the amplitude of COP displacement. Moreover, during the consecutive acoustic signals the weaker postural reactions were not always observed when the main stimulus was preceded by the prepulse (Figure 4).

The differences in reactions on startle and prepulse stimulus are shown on an exemplary stabilogram (Figure 5). A short time after the strong stimulus, the amplitude of COP displacement is significantly larger than in the case when the strong stimulus is preceded by prepulse.

\section{Discussion}

The results of this study show that unexpected acoustic stimulus of appropriate intensity elicits the startle response, which can be registered with the use of stabilographic platform. The presence of prepulse signal of a lower intensity causes the inhibition of postural reaction. Interestingly, such prepulse inhibition is only present in case of eyes open trials in ML plane.

The importance of visual information in the process of postural control is well documented, and together with the gravitational field it states extrinsic reference frame for the intrinsic mechanisms of postural control [21]. Previous studies concerning the process of postural control indicate its decline in case of lack of visual control [22-25]. It is possible that in trials with eyes closed, the startle response is masked by the higher indices of postural sway.

The statistically insignificant influence of prepulse on the inhibition of postural reaction in case of AP direction can be also caused by the masking effect of the startle response by the higher indices of postural sway in the sagittal plane. It is commonly known that postural sway in the sagittal plane is larger than in the frontal plane.

It seems that necessary condition to register prepulse inhibition with the use of posturographic platform is a strong startle response to the acoustic stimulus, characterized by the distinct postural reaction. Stronger reaction could be provoked by using higher intensity signals, exceeding $106 \mathrm{~dB}$. Such sound profiles were used in other studies [26-28].

The magnitude of postural sway can be also determined by the initial position of subjects. Brown et al. [17] reported in their study that the startle response caused by acoustic stimulus is dependent on body position and muscle activation. Authors registered different EMG profiles of leg muscles (tibialis anterior, soleus) in standing and sitting position in response to an acoustic stimulus.

Startle response observed with the use of force platform, as an effect of acoustic stimuli, was also examined by Hillman et al. [29]. They indicated a positive correlation of blinking 


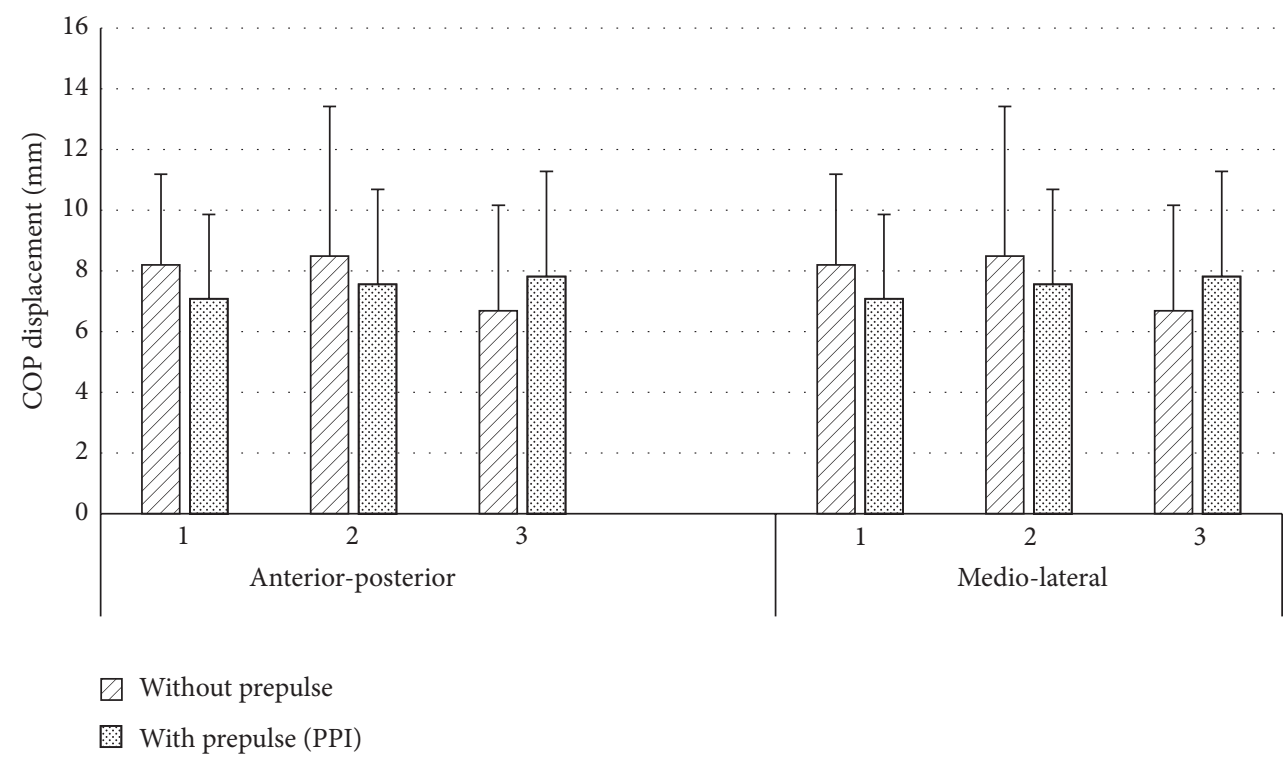

Figure 4: COP displacement depending on the kind (without Prepulse, with Prepulse) and order $(1,2,3)$ of the acoustic stimulus in eyes closed trials.

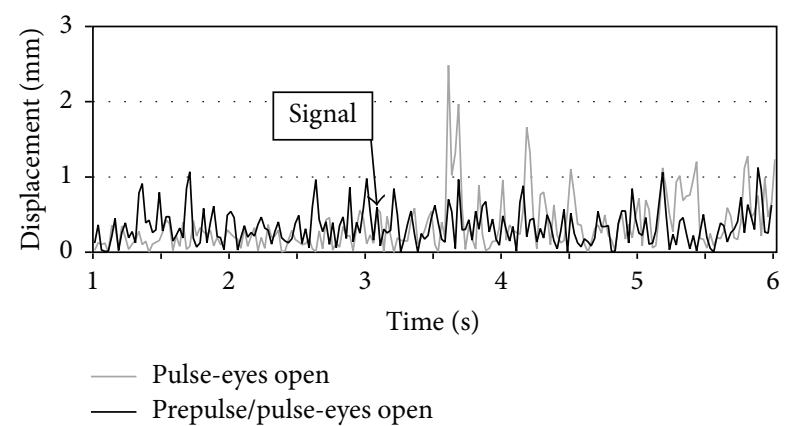

FIGURE 5: An exemplary stabilogram of COP displacement depicting the startle response caused by an unexpected acoustic signal (pulse) and its inhibition in case of prepulse signal.

reflex and whole body startle. Stronger blinking reflex correlated with a stronger general response. This relationship was observed only in the sagittal plane. According to these authors a distinct postural reaction caused by an unexpected acoustic stimulus can elicit general flexors activation. In our research stronger acoustic startle response was also noticed in the AP plane, as indicated by the greater COP displacement. However, significant prepulse inhibition was found only in the frontal plane (mediolateral). It may be another indication that excessive COP displacement impede the assessment of prepulse inhibition (masking effect).

The dependency between whole body startle response and blinking in the presence of unexpected stimulus reported by Hillman et al. [29] as well as our previous studies indicates that the static posturography methods can be an alternative to the electromyography of muscles during the assessment of sensorimotor gating and diagnosis of certain psychic and neurological disorders. It should be noticed that startle reflex is generalized reaction which includes multiple muscle group at the same time, and therefore it seems necessary to its global assessment, which is possible using posturography. Whole body startle response examination can be also very important in sports activities especially in case of the reactions to the start signals. However, the use of static posturography in neurological and sports diagnosis needs further experiments in order to improve the procedure.

Implication for Further Studies. Our study provides new approach of the assessment of startle response and its prepulse inhibition using posturography. Further studies are needed to improve and standardize this type of procedures (that includes a large sample size, both genders, and, above all, synchronous measurement of electromyography and posturography).

\section{Conclusions}

(1) Static posturography allows registration of postural sway due to startle response effects in humans.

(2) The significant weakening of the startle reaction in the presence of prepulse stimulus is observed in mediolateral plane with eyes open.

(3) Static posturography can be used as a simple effective method in the assessment of sensorimotor gating in humans. It is necessary to improve and standardize the testing procedures.

\section{Competing Interests}

All the authors declare no competing interests. 


\section{Acknowledgments}

This study was supported by a research grant from the Academy of Physical Education in Katowice.

\section{References}

[1] J. K. Wynn, M. J. Sergi, M. E. Dawson, A. M. Schell, and M. F. Green, "Sensorimotor gating, orienting and social perception in schizophrenia," Schizophrenia Research, vol. 73, no. 2-3, pp. 319-325, 2005.

[2] S. G. Ewing and A. A. Grace, "Evidence for impaired sound intensity processing during prepulse inhibition of the startle response in a rodent developmental disruption model of schizophrenia," Journal of Psychiatric Research, vol. 47, no. 11, pp. 16301635, 2013.

[3] H. Takahashi, M. Iwase, R. Ishii et al., "Impaired prepulse inhibition and habituation of acoustic startle response in Japanese patients with schizophrenia," Neuroscience Research, vol. 62, no. 3, pp. 187-194, 2008.

[4] B. B. Quednow, I. Frommann, J. Berning, K.-U. Kühn, W. Maier, and M. Wagner, "Impaired sensorimotor gating of the acoustic startle response in the prodrome of schizophrenia," Biological Psychiatry, vol. 64, no. 9, pp. 766-773, 2008.

[5] R. Wu, L. Song, J. Lü et al., "Prepulse inhibition of startle reflex in schizophrenics and healthy adults," National Medical Journal of China, vol. 95, no. 11, pp. 823-826, 2015.

[6] A. Ueki, K. Goto, N. Sato, H. Iso, and Y. Morita, "Prepulse inhibition of acoustic startle response in mild cognitive impairment and mild dementia of Alzheimer type," Psychiatry and Clinical Neurosciences, vol. 60, no. 1, pp. 55-62, 2006.

[7] M. Zoetmulder, H. B. Biernat, M. Nikolic, L. Korbo, and P. J. Jennum, "Sensorimotor gating deficits in multiple system atrophy: comparison with Parkinson's disease and idiopathic REM sleep behavior disorder," Parkinsonism and Related Disorders, vol. 20, no. 3, pp. 297-302, 2014.

[8] M. Zoetmulder, H. B. Biernat, M. Nikolic, L. Korbo, L. Friberg, and P. J. Jennum, "Prepulse inhibition is associated with attention, processing speed, and 123I-FP-CIT SPECT in Parkinson's Disease," Journal of Parkinson's Disease, vol. 4, no. 1, pp. 77-87, 2014.

[9] M. E. Kiziltan, A. Gunduz, H. Apaydin, S. Ertan, and G. Kiziltan, "Auditory startle reflex and startle reflex to somatosensory inputs in generalized dystonia," Clinical Neurophysiology, vol. 126, no. 9, pp. 1740-1745, 2015.

[10] G. F. Madsen, N. Bilenberg, J. R. Jepsen, B. Glenthøj, C. Cantio, and B. Oranje, "Normal P50 gating in children with autism, yet attenuated P50 amplitude in the asperger subcategory," Autism Research, vol. 8, no. 4, pp. 371-378, 2015.

[11] A. Aluja, A. Blanch, E. Blanco, and F. Balada, "Affective modulation of the startle reflex and the reinforcement sensitivity theory of personality: the role of sensitivity to reward," Physiology and Behavior, vol. 138, pp. 332-339, 2015.

[12] H. Takahashi, M. Iwase, Y. Yasuda et al., "Relationship of prepulse inhibition to temperament and character in healthy Japanese subjects," Neuroscience Research, vol. 72, no. 2, pp. 187193, 2012.

[13] M. Moriwaki, T. Kishi, H. Takahashi et al., "Prepulse inhibition of the startle response with chronic schizophrenia: a replication study," Neuroscience Research, vol. 65, no. 3, pp. 259-262, 2009.
[14] S. Schumacher, U. Schnyder, M. Furrer et al., "Startle reactivity in the long-term after severe accidental injury: preliminary data," Psychiatry Research, vol. 210, no. 2, pp. 570-574, 2013.

[15] M. Kandemir, A. Gündüz, N. Uzun, N. Yeni, and M. Kızıltan, "Auditory startle response is normal in juvenile myoclonic epilepsy," Neurological Sciences, vol. 36, no. 7, pp. 1247-1249, 2015.

[16] H. Kumru, E. Opisso, J. Valls-Solé, and M. Kofler, "The effect of a prepulse stimulus on the EMG rebound following the cutaneous silent period," Journal of Physiology, vol. 587, no. 3, pp. 587-595, 2009.

[17] P. Brown, B. L. Day, J. C. Rothwell, P. D. Thompson, and C. D. Marsden, "The effect of posture on the normal and pathological auditory startle reflex," Journal of Neurology, Neurosurgery and Psychiatry, vol. 54, no. 10, pp. 892-897, 1991.

[18] T. Daldrup, J. Remmes, J. Lesting et al., "Expression of freezing and fear-potentiated startle during sustained fear in mice," Genes, Brain and Behavior, vol. 14, no. 3, pp. 281-291, 2015.

[19] J. W. Blłaszczyk and K. Tajchert, "Effect of acoustic stimulus characteristics on the startle response in hooded rats," Acta Neurobiologiae Experimentalis, vol. 57, no. 4, pp. 315-321, 1997.

[20] C. Grillon, R. Ameli, D. S. Charney, J. Krystal, and D. Braff, "Startle gating deficits occur across prepulse intensities in schizophrenic patients," Biological Psychiatry, vol. 32, no. 10, pp. 939-943, 1992.

[21] J. Massion, "Movement, posture and equilibrium: interaction and coordination," Progress in Neurobiology, vol. 38, no. 1, pp. 35-56, 1992.

[22] J. J. Collins and C. J. De Luca, "The effects of visual input on open-loop and closed-loop postural control mechanisms," Experimental Brain Research, vol. 103, no. 1, pp. 151-163, 1995.

[23] L. Nashner and A. Berthoz, "Visual contribution to rapid motor responses during postural control," Brain Research, vol. 150, no. 2, pp. 403-407, 1978.

[24] W. M. Paulus, A. Straube, and T. Brandt, "Visual stabilization of posture. Physiological stimulus characteristics and clinical aspects," Brain, vol. 107, no. 4, pp. 1143-1163, 1984.

[25] H. SIenkiewicz, "The comparison of stabilogram courses for human keeping balance after the elimination of some sense functions," Human Movement, vol. 2, no. 4, pp. 39-50, 2001.

[26] P. A. Csomor, F. X. Vollenweider, J. Feldon, and B. K. Yee, "On the feasibility to detect and to quantify prepulse-elicited reaction in prepulse inhibition of the acoustic startle reflex in humans," Behavioural Brain Research, vol. 162, no. 2, pp. 256263, 2005.

[27] K. Ludewig, S. Ludewig, A. Seitz, M. Obrist, M. A. Geyer, and F. $\mathrm{X}$. Vollenweider, "The acoustic startle reflex and its modulation: effects of age and gender in humans," Biological Psychology, vol. 63, no. 3, pp. 311-323, 2003.

[28] N. Putzki, K. Graf, P. Stude, H.-C. Diener, and M. Maschke, "Habituation of the auditory startle response in cervical dystonia and Parkinson's disease," European Neurology, vol. 59, no. 3-4, pp. 172-178, 2008.

[29] C. H. Hillman, E. T. Hsiao-Wecksler, and K. S. Rosengren, "Postural and eye-blink indices of the defensive startle reflex," International Journal of Psychophysiology, vol. 55, no. 1, pp. 4549, 2005. 

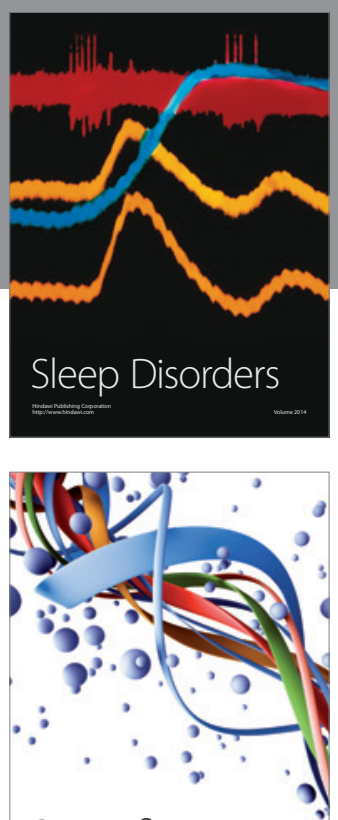

Scientifica
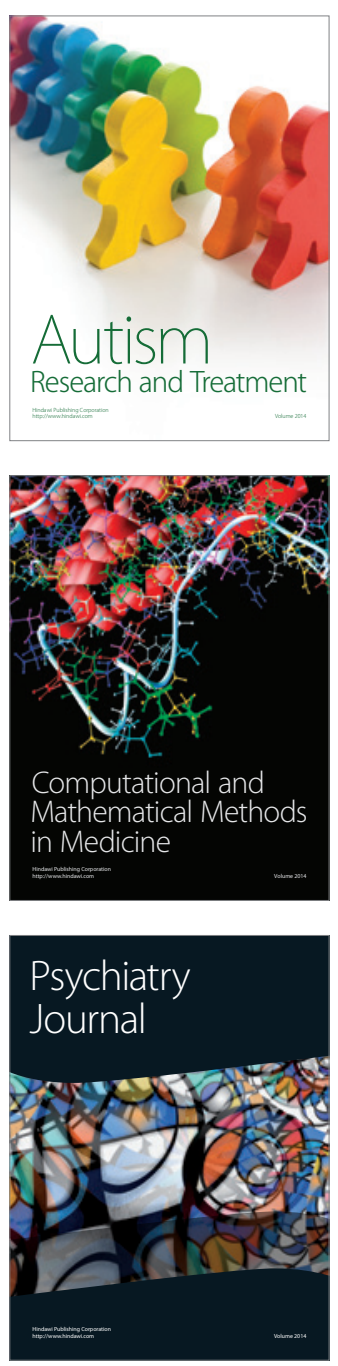
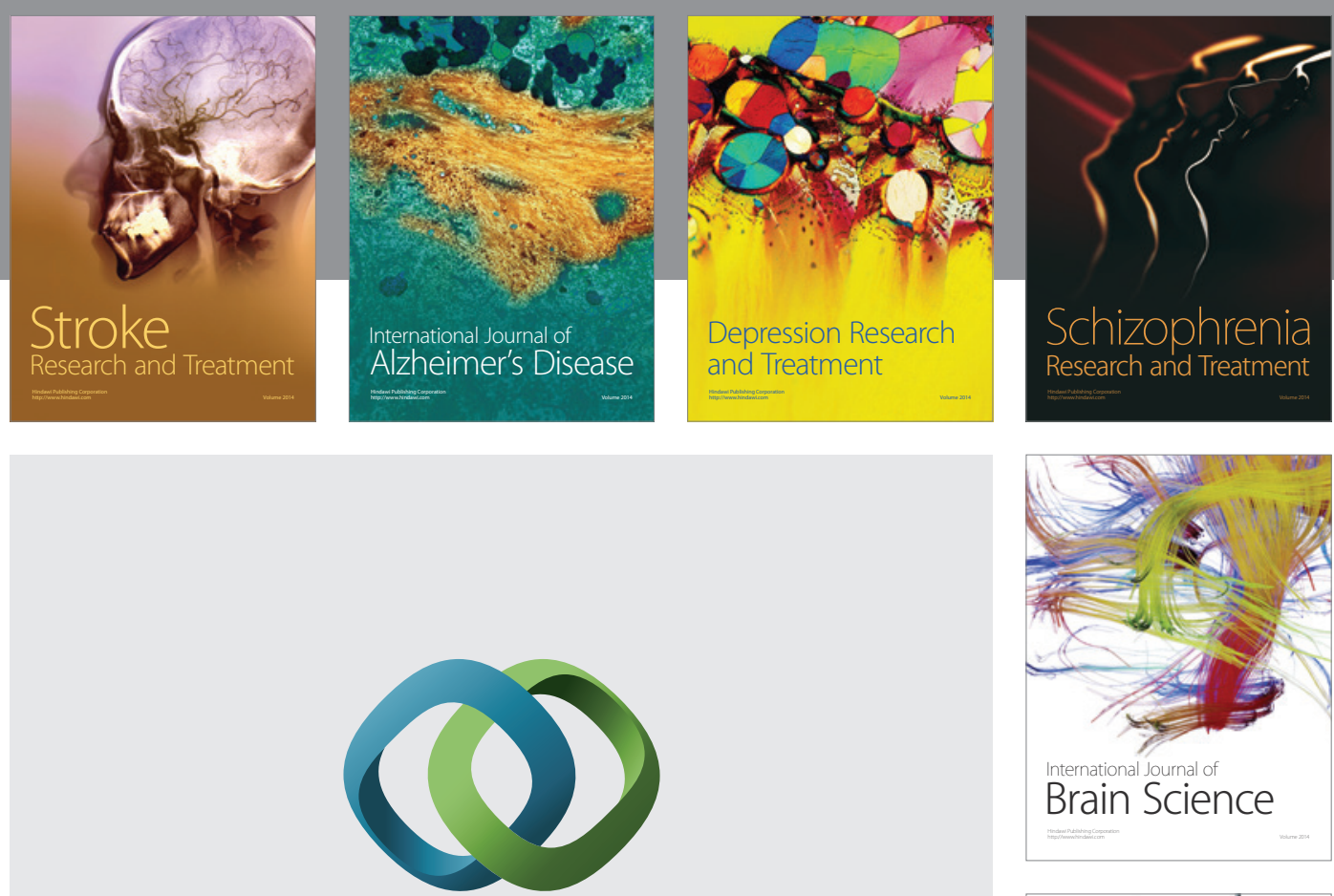

\section{Hindawi}

Submit your manuscripts at

http://www.hindawi.com
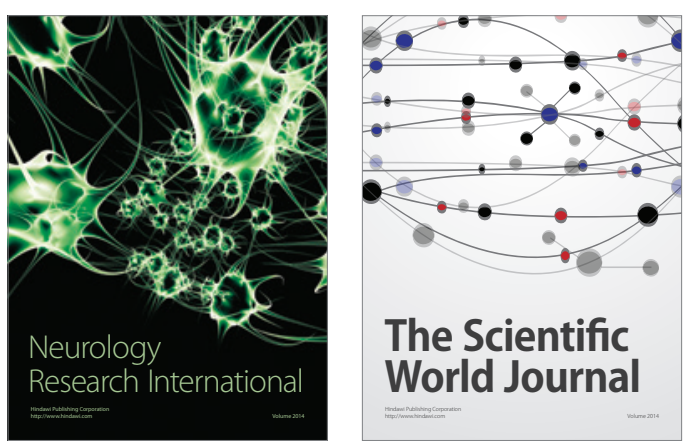

The Scientific World Journal

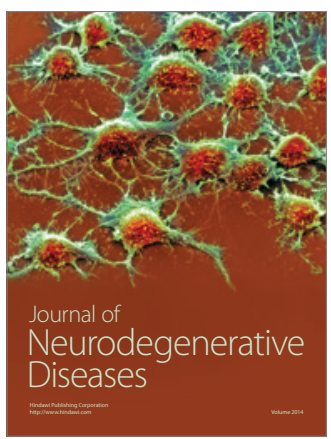

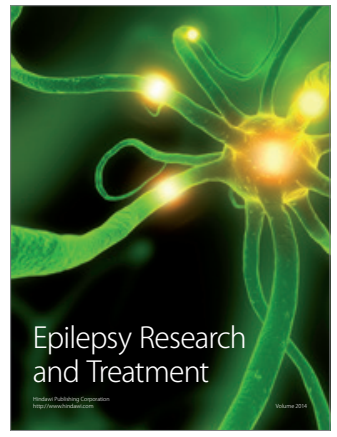

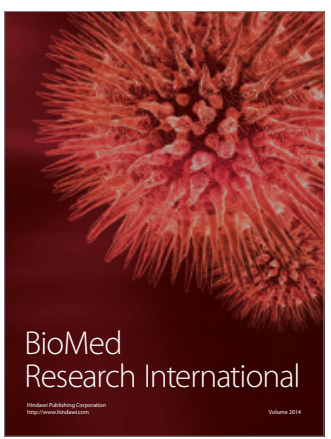

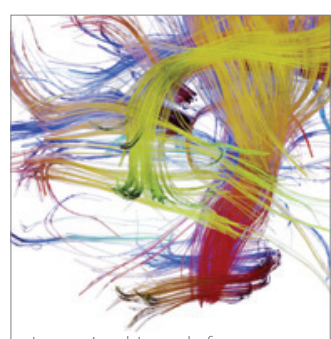

Brain Science

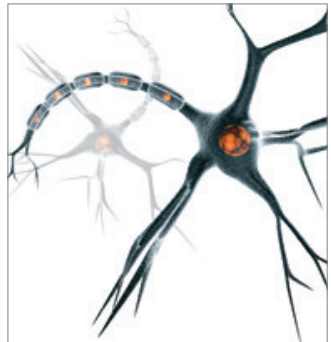

Neural Plasticity
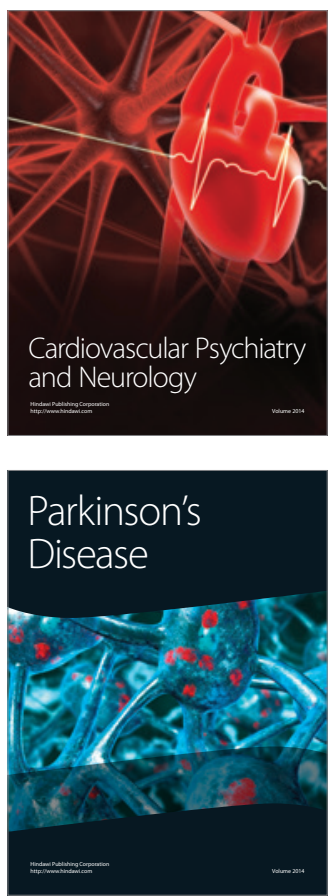